\title{
Comparison of movement velocity and force-velocity parameters using a free video analysis software and a linear position transducer during unilateral and bilateral ballistic leg press
}

\author{
Klimentini Martinopoulou, Athanasios Tsoukos, Olyvia Donti, Christos Katsikas, Gerasimos Terzis, \\ Gregory C. Bogdanis
}

Sports Performance Laboratory, School of Physical Education \& Sport Science, National \& Kapodistrian University of Athens, Greece

\begin{abstract}
Study aim: This study compared movement velocity and force-velocity profile parameters measured by a free video analysis software program, with the use of a high-speed video recording, and a validated linear position transducer (LPT).

Material and methods: Ten team-sports athletes performed double-leg and single-leg ballistic lower limb extensions on a leg press machine against a wide range of resistive loads. Each repetition was recorded by the LPT a high-speed camera (300 fps), and later analysed with a free video analysis software program.

Results: Mean and peak movement velocity presented high reliability (ICC: 0.990 and 0.988, p < 0.001) and agreement between the two measuring systems (systematic bias: $-0.06 \pm 0.04$ and $-0.01 \pm 0.03 \mathrm{~m} / \mathrm{s}$, respectively). Force-velocity profile parameters were also similar: maximum velocity at zero load (Vo: $1.79 \pm 0.15 \mathrm{vs} .1 .78 \pm 0.12 \mathrm{~m} / \mathrm{s}, \mathrm{p}=0.64$ ), slope (b: $-1585 \pm 503$ vs. $-1562 \pm 438 \mathrm{~N} \cdot \mathrm{s} / \mathrm{m}, \mathrm{p}=0.43)$, maximum force at zero velocity (Fo: $2835 \pm 937$ vs. $2749 \pm 694 \mathrm{~N}, \mathrm{p}=0.41)$ and maximum power $(1274 \pm 451$ vs $1214 \pm 285 \mathrm{~W}, \mathrm{p}=0.38)$. Both measuring systems could similarly detect the individual force or velocity deficit $(\mathrm{p}=0.91)$.

Conclusion: In conclusion, a free video analysis software combined with a high-speed camera was shown to be a reliable, accurate, low bias and cost-effective method in velocity-based testing.
\end{abstract}

Keywords: Force-velocity relationship - Velocity-based training - Power training

\section{Introduction}

Velocity based resistance training (VBRT) is a new popular method used by strength and conditioning coaches to minimize and control neuromuscular fatigue during strength training and maximize strength and hypertrophic adaptations [24]. VBRT typically involves the utilization of a linear position encoder or a linear velocity transducer, to monitor the velocity of movement of the barbell in every repetition when the participant is performing resistance exercise and thus to optimize the volume load via a percentage drop of velocity from the fastest repetition $[2,13]$. Generally, linear position or velocity transducers are considered reliable and accurate devices [9, 10, 13, 23]. However, their high cost and difficult portability, as well as the requirement to operate them using a computer or tablet makes their use at certain circumstances, not so easy for practical use. On the other hand, high speed video cameras (included in smartphones) in combination with kinematic software or smartphone applications are more affordable and easy-to use, while their video capturing systems are able of high speed recording (120-300 frames per secondfps) compared with the standard types of video cameras (30 fps), thus allowing for more accurate measurements $[4,17,25,34]$.

Some studies examined the relationship between smartphone applications and linear position transducers (LPTs) and found that the validity of applications depends on the recording frequency of the camera $[3,17]$. For example, Kasovic et al. [17] measured the average concentric velocity with a smartphone application and compared the values with the validated linear position transducer during the front and back squat and conventional and sumo deadlift. The authors found that the smartphone application gave significantly lower average concentric velocity 
values compared with the validated linear position transducer [17]. However, the authors stated that the recording speed of the camera was very low (i.e. $30 \mathrm{fps}$ ), and this explained the lower velocity values. In contrast, BalsalobreFernandez et al. [3] compared a LPT with another smartphone application with a recording speed of $240 \mathrm{fps}$ and found that the smartphone application was valid, reliable, and accurate for the measurement of barbell velocity in the bench-press, full-squat, and hip-thrust exercises.

Recently, simple methods of measuring movement velocities during resistance exercise have enabled the frequent and easy determination of the force-velocity profiles $[12,16,27,29,36,37]$ and load-velocity relationships in order to create generalized equations for the estimation of maximum strength (1RM) and \%1RM from movement velocity $[7,11,14,15,21,26,28,32,33,35]$. These approaches provide strength and conditioning coaches with useful information to monitor adaptations and adjust strength training programs. In the literature, there is no study that has evaluated the movement velocity and force - velocity parameters on different devices (LPT and video), using different software applications, including freeof-charge solutions. This would provide practitioners with a useful, effective and low-cost approach, for monitoring training and performance during resistance training. Therefore, the aim of this study was to compare the movement velocity and force - velocity profile parameters measured by a free video analysis software program (VA) with the use of a high recording speed (300 fps), with a validated linear position transducer (LPT).

\section{Material and methods}

\section{Experimental design}

Ten team sports athletes ( 5 males and 5 females age: $23.3 \pm 4.1$ years, body mass $68.9 \pm 9.3 \mathrm{~kg}$, basketball, and soccer players) performed double and single leg concentric ballistics extensions on a leg press machine (Leg-press, Super-Sport SA, Greece) in a series of 5 different loads providing a wide range of mean velocity values of the movement $(0.34-1.53 \mathrm{~m} / \mathrm{s})$, with loads ranging from 35 to 106 $\mathrm{kg}$. The leg press machine allows movement in only one direction compared to the free weights which do not follow a predetermined path, making the evaluation more reliable [8]. Also, even novice participants can perform maximal-effort ballistic extensions in contrast with other exercises such as squat jumps (using free weights or in a smith machine) which require a level of skill in order to have correct execution [21]. Each repetition was simultaneously recording using a LPT (Tendo Power Analyzer System v. 314, TENDO Sports Machines, Trencin, Slovak Republic) and a highspeed camera. Movement velocity and force were obtained from the LPT software. The video analysis was performed using a free software program (Tracker 5.0.6), and velocity, acceleration and force were then calculated. Force-velocity parameters were also calculated and compared using the LPT and video analysis data.

\section{Subjects}

Ten team sport athletes (basketball and soccer, 5 males and 5 females) participated in this investigation $(23.3 \pm 4.1$ years, $69.3 \pm 8.5 \mathrm{~kg})$. After a thorough explanation of the testing protocol, the possible risks involved and the right to cease the participation at will, a written informed consent was obtained from each participant. All procedures were performed in accordance with the principles outlined in the Declaration of Helsinki and were approved by the local ethics committee (ref. number: 1145/19).

\section{Procedures}

On the first two visits, participants were familiarized with the ballistic movement on a leg press machine (Fig. 1). Participants were seated on a leg machine which

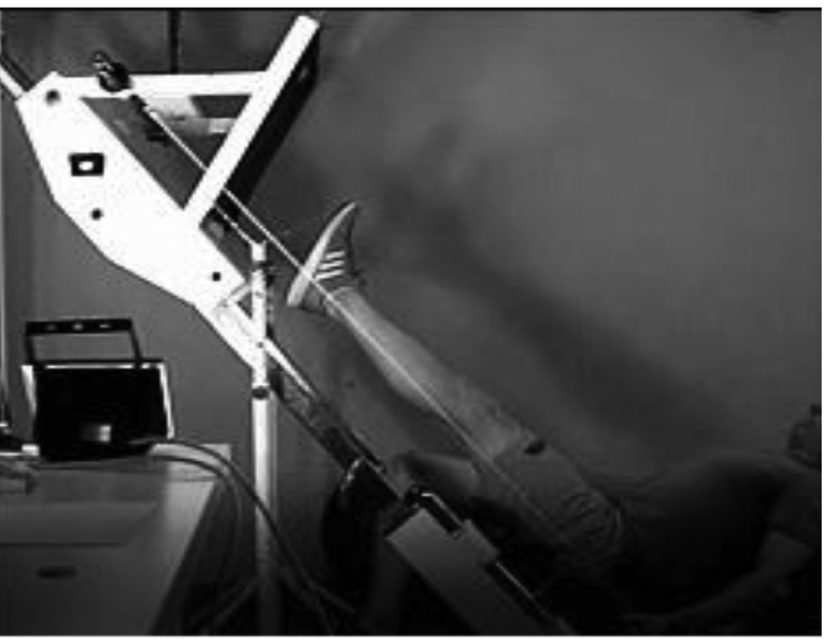

Figure 1. Leg press machine ballistic extension 
consist an immovable chair seat with the seat inclined back at $110^{\circ}$ allowing the leg extension in a diagonal direction $\left(45^{\circ}\right)$, pushing a weight rack platform. Three days after the last familiarization visit, the main testing session was conducted. Participants were fastened on the seat to eliminate any other movement. Knee angle was set at $108 \pm 2^{\circ}$ corresponding to a push off distance $20 \pm 2 \mathrm{~cm}$ calculated as the displacement of the platform from the starting position until full knee extension with lower limb at maximal plantar flexion [30]. Prior to the main testing, the individual push off distance was calculated as mentioned above. On the main test session, participants executed firstly 2 trials of double-leg extensions with 5 different and increasing loads. This was followed by single-leg trials (two for each leg), against 5 different and increasing loads. Resistive load was calculated in the direction of movement load [(i.e. load $\mathrm{x}$ $\left.\sin \left(45^{\circ}\right)\right]$. For females, resistive load in the first double-leg and the first single-leg extension was $42.5 \mathrm{~kg}$ and $35 \mathrm{~kg}$, respectively. Thereafter, load was increased by $11.25 \mathrm{~kg}$, resulting in a range of 42.5 to $87.5 \mathrm{~kg}$ for double-leg trials and 35 to $80 \mathrm{~kg}$ for the single-leg trials. For males, resistive load in the first double-leg and the first single-leg extension was $46.25 \mathrm{~kg}$ and $35 \mathrm{~kg}$, respectively. Thereafter, load was increased by $15 \mathrm{~kg}$, resulting in a range of 46.25 to 106.15 $\mathrm{kg}$ for double-leg trials and 35 to $100 \mathrm{~kg}$ for the single-leg trials. The rest interval was 2 minutes between repetitions and 5 minutes from double to single leg repetitions. Before each familiarization and testing session, participants performed a standardized warm-up consisting of $10 \mathrm{~min}$ utes of light cycling against a standard load $(60 \mathrm{~W})$ and 5 minutes of dynamic stretching of the lower limb muscles. Participants were asked to avoid any exercise for 48 hours before and during testing procedure.

\section{Measurement equipment and data acquisition}

Each of the 300 repetitions (10 trials double leg and 10 trials each single leg) was simultaneously recorded using a linear position transducer (Tendo Unit; Trencin, Slovak Republic) and a high-speed camera (Casio Exilim Pro EX-F1) with a sampling frequency $300 \mathrm{fps}$. LPT instantaneous displacement, velocity and force were obtained every $1 \mathrm{~cm}$ via the provided Tendo software. A marker was placed on the leg press machine and videos were analysed with a freely available software program (Tracker 5.0.6) providing a semi-automatic tracking displacement - time function at $300 \mathrm{fps}$, which was checked by visual observation of displacement - time data on a graph. Each video analysis was preceded by a calibration using a reference system of $1 \mathrm{~m}$ including vertical and horizontal segments in the movement plane. The time - displacement data from tracker were imported into a spreadsheet to calculate instant velocity and acceleration from the derivative of the displacement - time $(\mathrm{V}=\mathrm{ds} / \mathrm{dt})$ and velocity - time $(\mathrm{a}=\mathrm{dv} / \mathrm{dt})$ data. Instantaneous force was calculated from the equation: $\mathrm{F}=$ load $^{*} \mathrm{~g}+$ load*a (where $\mathrm{a}=$ acceleration and $g=9.81 \mathrm{~m} / \mathrm{sec}^{2}$ ). The start of the movement was set at the point where displacement exceed $0.005 \mathrm{~m}$. Raw data were filtered using a low-pass, 4th order, zero lag Butterworth digital filter with a cut-off frequency of $8 \mathrm{~Hz}$. Movement velocity was calculated as the mean velocity $($ Vmean $=$ push off displacement $/$ push off time $)$ and peak velocity (highest velocity value), while force was taken as the average force during the push off. Force-velocity profile parameters were assessed from the double leg data using the average values ( 2 trials for each load). The linear regressions were extrapolated to determine individual Fo (intercept), $b$ (slope of the regression), $\mathrm{Vo}=\mathrm{Fo} / \mathrm{b}$ and Pmax $=\mathrm{FoVo} / 4$. Optimum slope of the force-velocity relationship (FVopt) and force-velocity imbalance (FVimb $=$ b/FVopt*100) were calculated from the equations Samozino, Morin and colleagues $[22,31]$ with values higher than $100 \%$ indicating a velocity deficit and lower than $100 \%$ indicating a force deficit.

\section{Statistical analyses}

The reliability of peak and mean movement velocity for all LPT and all high-speed camera trials, was examined using a two-way mixed intraclass correlation coefficient (ICC) model. Reliability and accuracy of movement velocity between the two measuring systems was examined from all repetitions ( 2 trials each load $n=300$ ). Relative reliability was assessed with linear regression through the correlation coefficient (R) and the standard error of estimate (SEE) [1]. The agreement - accuracy between both devices for movement velocity was examined with Bland-Altman plots using the mean difference of the two systems and $95 \%$ limits of agreement (LoA) [5]. The presence of fixed bias was examined with one sample t-test of differences and proportional bias from the slope (b) of the linear regression between the system means and differences $[19,20]$. Paired t-tests $(\mathrm{N}=10)$ were conducted to compare force - velocity profile parameters (Fo, Vo, Pmax, FVopt) between the two systems. For pairwise comparisons, effect size was determined by Cohen's $d$ (trivial: $<0.2$, small: $\geq 0.2$, medium: $\geq 0.5$, large: $\geq 0.8)[6,18]$. Descriptive data are presented as means and SD. Statistical significance was accepted at the $\alpha=0.05$ level, and confidence limits were set at $95 \%$. Statistical analyses were carried out using SPSS (IBM SPSS Statistics Version 25).

\section{Results}

Linear position transducer and VA showed a very high reliability (ICC) of mean and peak velocity determination (Table 1). The agreement between the two systems is shown in Figures 2, 3, 4 and 5. The two measuring methods were highly correlated (Vmean $\mathrm{r}^{2}=0.97$, Vpeak $\mathrm{r}^{2}=0.98$, 
Table 1. Intraclass coefficient correlation (ICC), standard error of measurement (SEM) and \% SEM

\begin{tabular}{|c|c|c|c|c|c|c|}
\hline \multirow[b]{2}{*}{ Variable } & \multicolumn{3}{|c|}{ LPT } & \multicolumn{3}{|c|}{ VIDEO } \\
\hline & $\mathrm{ICC}$ & SEM & $\%$ SEM & $\mathrm{ICC}$ & SEM & $\%$ SEM \\
\hline Vmean & 0.990 & 0.02 & $2.5 \%$ & 0.987 & 0.02 & $2.7 \%$ \\
\hline Vpeak & 0.988 & 0.035 & $3.6 \%$ & 0.992 & 0.03 & $2.0 \%$ \\
\hline
\end{tabular}

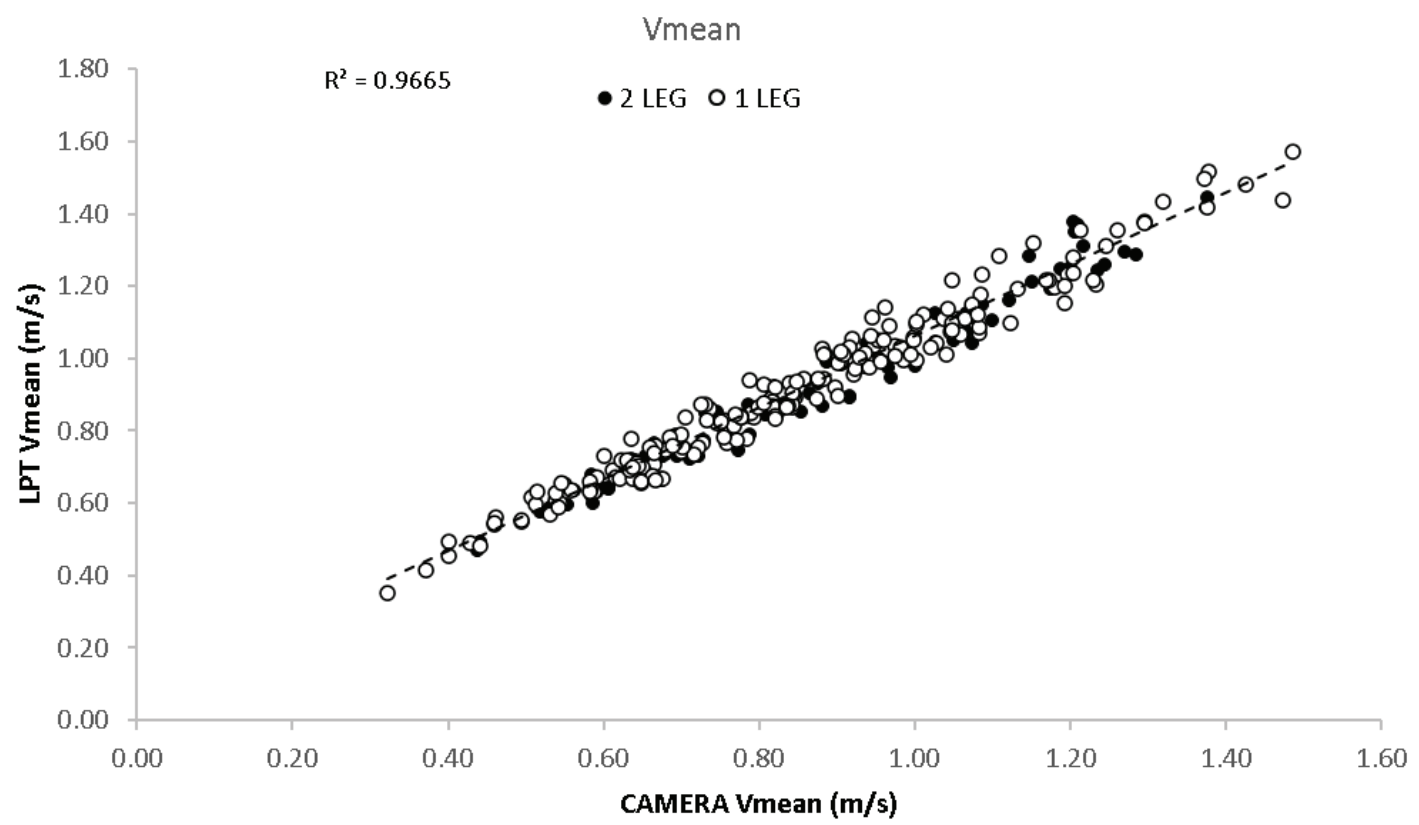

Figure 2. Push off mean movement velocity correlation between LPT and high-speed video camera. Filled circles indicate double leg and open circles single leg mean velocities. Vmean: mean push off velocity

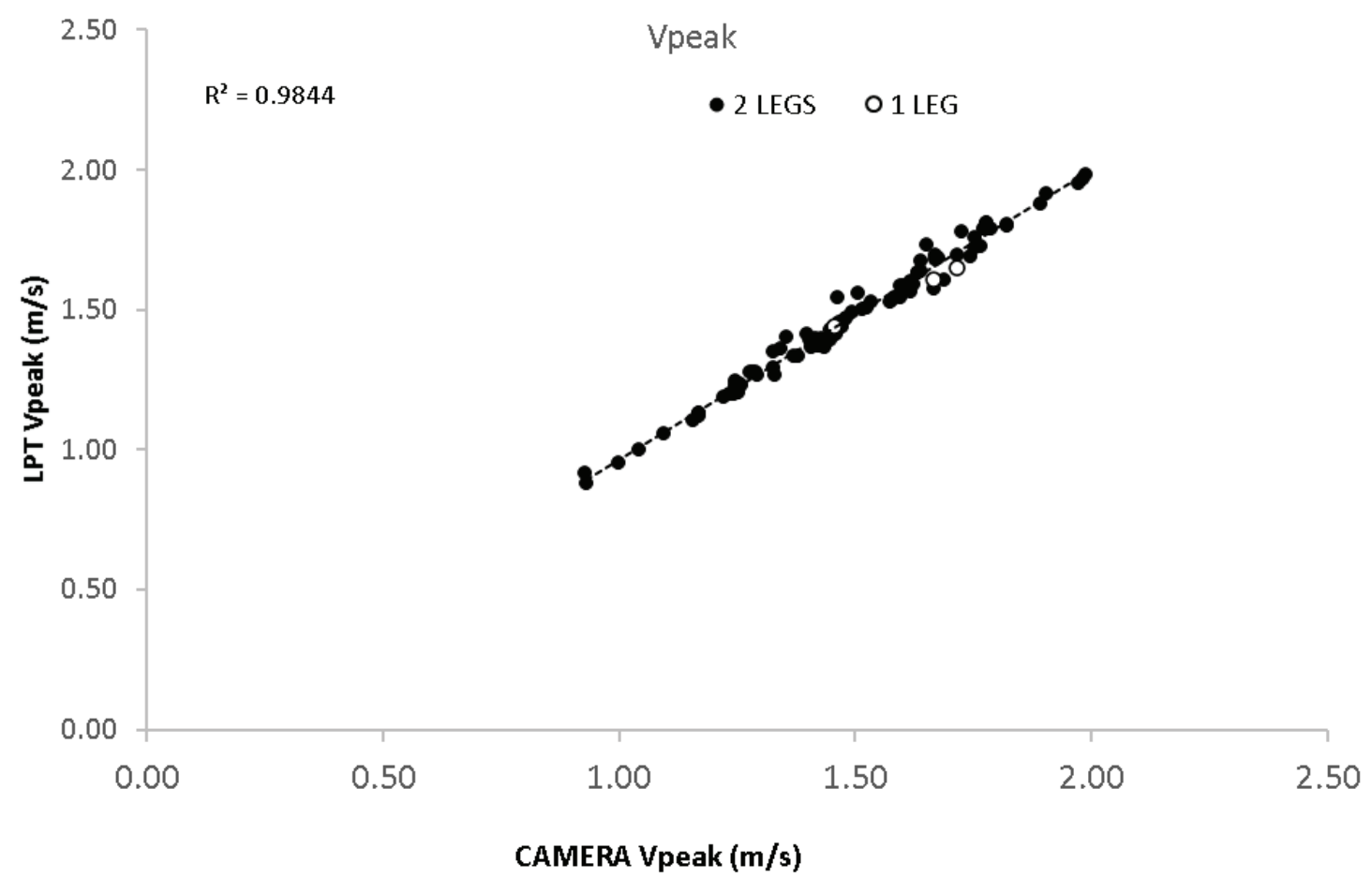

Figure 3. Push off peak movement velocity correlation between LPT and high-speed video camera. Filled circles indicate double leg and open circles single leg mean velocities. Vpeak: peak push off velocity 


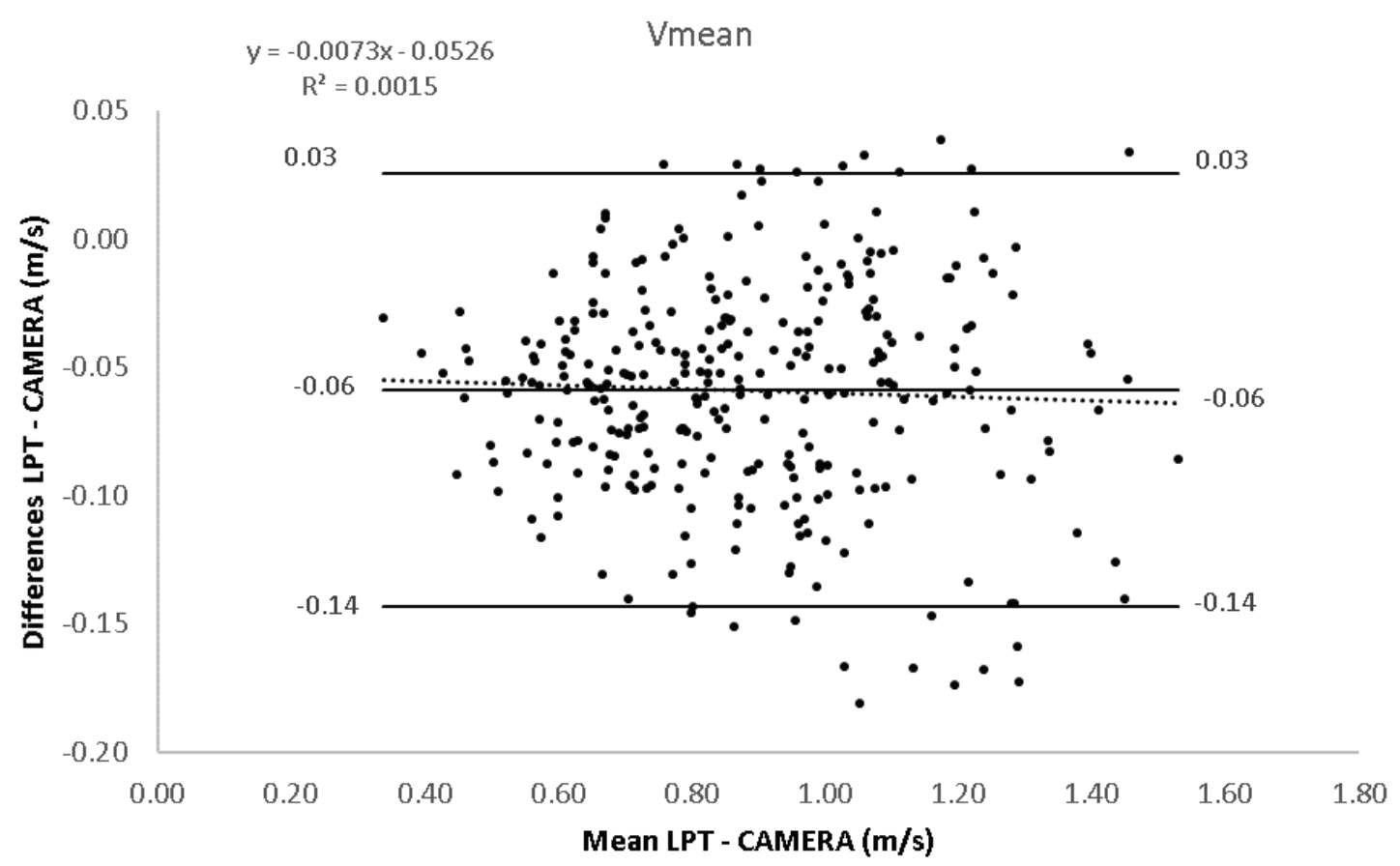

Figure 4. Bland-Altman plot of mean difference, $95 \%$ limits of agreement $(0.03$ to $-0.14 \mathrm{~m} / \mathrm{s}$, black lines $)$ and linear regression between LPT and camera for push off mean movement velocity

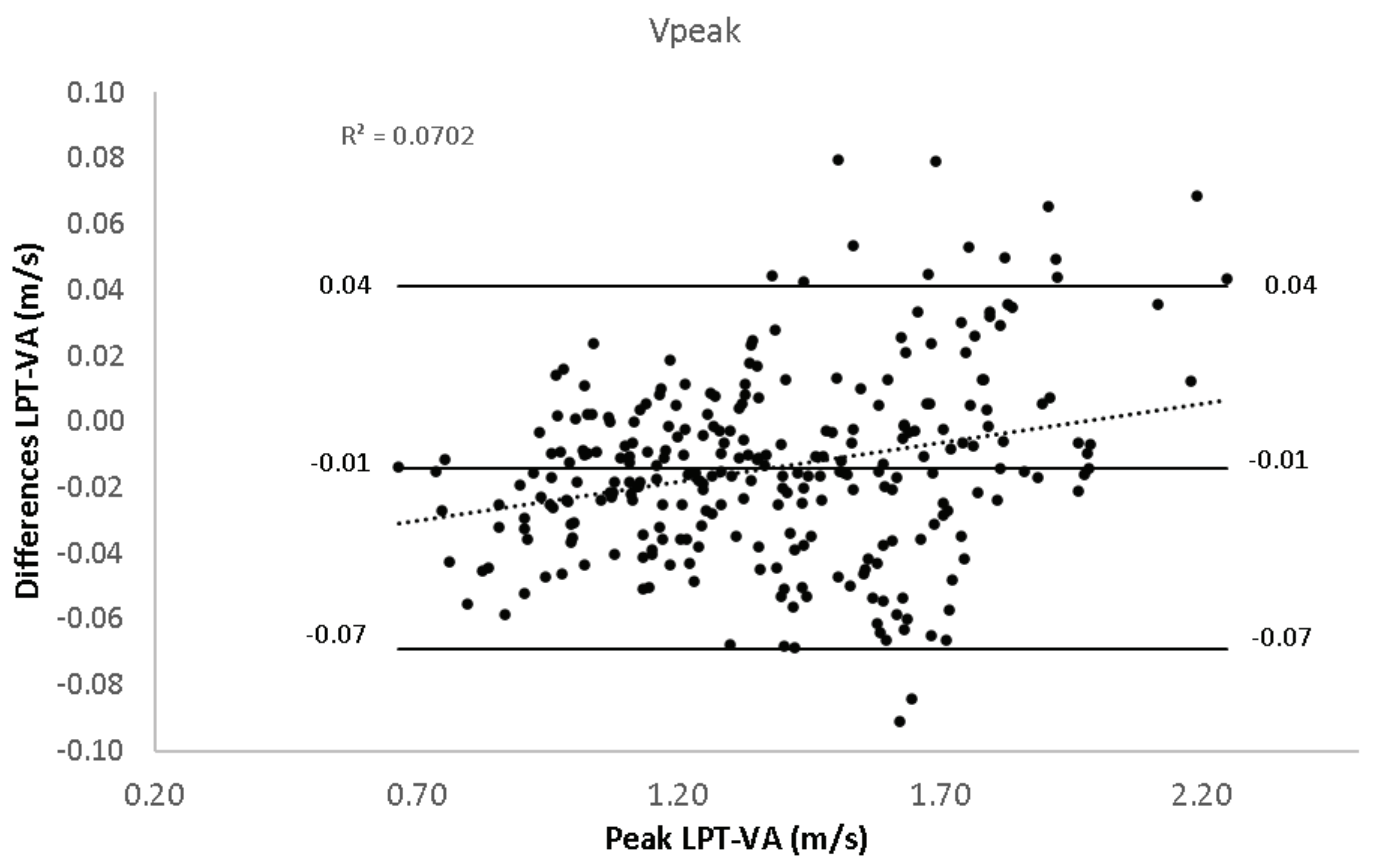

Figure 5. Bland-Altman plot of mean difference, $95 \%$ limits of agreement $(0.03$ to $-0.14 \mathrm{~m} / \mathrm{s}$, black lines $)$ and linear regression between LPT and camera for push off peak movement velocity

$\mathrm{p}<0.001)$. The agreement of mean movement velocity between the two devices was examined using a Bland \& Altman plot, showing low LoA $(-0.14 \mathrm{~m} / \mathrm{s}$ to $0.03 \mathrm{~m} / \mathrm{s})$, small systematic bias with LPT presenting slightly lower values $(-0.06 \pm 0.04 \mathrm{~m} / \mathrm{s}, \mathrm{CI}:-0.06$ to $-0.05 \mathrm{~m} / \mathrm{s}, \mathrm{p}<0.05)$ and slightly non-proportional bias $(\mathrm{b}=-0.007, \mathrm{CI}$ : -0.03 to $0.01 \mathrm{~m} / \mathrm{s}, \mathrm{p}=0.50$ ) (Fig. 4). The agreement of peak movement velocity between the two devices showed low LoA $(-0.07 \mathrm{~m} / \mathrm{s}$ to $0.04 \mathrm{~m} / \mathrm{s})$, small systematic bias with LPT presenting slightly lower values $(-0.01 \pm 0.03 \mathrm{~m} / \mathrm{s}$, CI: -0.02 to $-0.01 \mathrm{~m} / \mathrm{s}, \mathrm{p}<0.05)$ and proportional bias (b $=0.02$, CI: 0.01 to $0.03 \mathrm{~m} / \mathrm{s}, \mathrm{p}<0.05$ ) (Fig. 5). Paired t-tests on double leg force-velocity profile characteristics showed that there was no difference between the two 
Table 2. Force-velocity parameters obtained using the linear position transducer (LPT) and the video analysis (VA) systems $(\mathrm{mean} \pm \mathrm{SD})$

\begin{tabular}{lcccc}
\hline & LPT & VA & p value & Cohen's d effect size \\
\hline Fo $[\mathrm{N}]$ & $2835 \pm 937$ & $2749 \pm 694$ & 0.41 & 0.11 \\
Vo $[\mathrm{m} / \mathrm{s}]$ & $1.79 \pm 0.15$ & $1.78 \pm 0.12$ & 0.64 & 0.10 \\
$\mathrm{~b}[\mathrm{~N} \cdot \mathrm{s} / \mathrm{m}]$ & $-1585 \pm 503$ & $-1562 \pm 438$ & 0.43 & 0.38 \\
Pmax $[\mathrm{W}]$ & $1274 \pm 451$ & $1214 \pm 285$ & 0.91 & 0.17 \\
FVimb $[\%]$ & $115.7 \pm 25.2 \%$ & $116 \pm 24.4 \%$ & & 0.01 \\
\hline
\end{tabular}

Fo: maximum force at zero velocity, b: slope of the force-velocity relationship, Vo: maximum velocity at zero load, Pmax: maximum power, FVimb: force-velocity imbalance

measuring systems for all force-velocity parameters (Table 2). Also, there was no difference in the calculation of FVimb $(\mathrm{p}=0.68, \mathrm{~d}=-0.04)$ between the two measuring systems. Four out of ten participants had a balanced forcevelocity profile (FVimb between 90 and $110 \%$ ), one had a mild force deficit (FVimb $<90 \%)$ and five had a velocity deficit (FVimb between 119 and 168\%). Both systems of measurement could similarly detect the individual force or velocity deficit (Table 2).

\section{Discussion}

The purpose of the present study was to compare the movement mean velocity and force - velocity profile parameters measured by a free video analysis software program with the use of a high recording speed (300 fps), with a previously validated linear position transducer. The results showed that movement velocity was similar when obtained using LPT and the VA. Also, both methods presented high reliability, low LoA and small systematic bias. Furthermore, no difference in the force - velocity profile parameters was observed between the LPT and the VA.

One possible reason for the high reliability and validity of the free video analysis software program might be the high recording speed (300 fps) of the camera used to obtain the videos. Kasovic et al. [17] used a regular camera operating at $30 \mathrm{fps}$ and found lower average concentric velocities when the analysis was performed using a smartphone application compared with the values of a validated linear position transducer during the front and back squat and conventional and sumo deadlift. On the other hand, Balsalobre-Fernandez et al. [3] showed that VA was highly valid, reliable, and accurate for the measurement of barbell velocity in the bench-press, full-squat, and hip-thrust exercises when the camera operating at $240 \mathrm{fps}$ compared with a LPT. Moreover, Perez-Castilla et al. [25] examined the reliability and validity of two LPTs to measure movement velocity during the bench press exercise and compared the values with a 3D optical motion sensing system which cameras operating at $120 \mathrm{fps}$. The authors found low systematic bias and random errors of the two LPTs compared with the 3D optical motion sensing system which cameras operating at $120 \mathrm{fps}$ and almost perfect relationships $(r>0.99 ; p<0.001)$ [25]. Thus, it seems that when using VA for VBT, the camera operating speed should be $120 \mathrm{fps}$ or greater.

Regarding the determination of training intensity with the use of VA, research has shown that a mean velocity bias from $0.13 \mathrm{~m} / \mathrm{s}$ to $0.20 \mathrm{~m} / \mathrm{s}$ could cause errors in the estimation of maximum strength (1RM) by $13.9 \%$ to $22.6 \%$ in the bench press exercise [34]. However, in our study the differences in mean movement velocity between the two measuring systems was small $(0.06 \mathrm{~m} / \mathrm{s})$. Thus the error of estimation of maximum strength with the free software is limited to $6-7 \%$ [14]. Also, it has been shown that high speed video cameras (digital cameras or smart phone cameras) produced significant overestimation $(>0.13 \mathrm{~m} / \mathrm{s})$ of barbell movement velocity especially at high velocities $>0.8 \mathrm{~m} / \mathrm{s}$ [34]. In the present study we used ballistic push offs, and the greater percentage of muscle actions was over $0.8 \mathrm{~m} / \mathrm{s}$ (Fig. 1) however the difference in mean and peak velocity were very small $(0.06$ and $0.01 \mathrm{~m} / \mathrm{s}$, respectively) compared with the above previous studies. A possible explanation of this result might be that in the study of Sanchez-Pay et al. [34] the beginning of the movement was considered as the first frame in which the barbell started to ascend vertically and at high speeds a lost frame might result in bigger discrepancy in time and displacement calculation hence and movement velocity. On the other hand, in our study the time - displacement data from Tracker software were imported into a spreadsheet and we set a fixed starting point of $0.005 \mathrm{~m}$ which seems to be methodologically sound and produce more consistent results.

To our knowledge, there is no study that has investigated force-velocity parameters (Fo, Vo, Pmax) and forcevelocity imbalance (FVimb) between different measuring systems. There was no difference in maximum velocity 
(Vo), force-velocity slope (b), force-velocity imbalance (FVimb), maximum force (Fo) and maximum power (Pmax) obtained using the LPT and the VA software package. This finding is very important, as strength and conditioning coaches or practitioners could test the progress of their athletes with the use only of a high-speed camera (which could be a smartphone camera) and adjust their training goals. Importantly, the automatic-tracking procedure of the free analysis software makes the procedure fast and accurate, provided that the appropriate markers and calibration are used. Provided that the analysis spreadsheets are prepared in advance, the video analysis methods require time to transfer the videos to a computer, import them to the free analysis software, run the auto tracking of a position marker and then transferring the data to the spreadsheet. It may be estimated that this procedure takes approximately $3-5$ min per trial.

In conclusion, this study showed that a free video analysis software combined with a high-speed camera may be a reliable, accurate, low bias and cost-effective method in velocity-based testing and training, even when used in high speed movements like the ballistic push offs. This method could be used to determine exercise intensity and to detect changes in the force-velocity profile of athletes during resistance training. However, it cannot be used for immediate feedback to athletes as it requires certain processing steps after the videos are recorded.

\section{Conflict of interest: Authors state no conflict of interest.}

\section{References}

1. Atkinson G., Nevill A.M. (1998) Statistical methods for assessing measurement error (reliability) in variables relevant to sports medicine. Sport. Med., 26: 217-238. DOI: 10.2165/00007256-199826040-00002.

2. Balsalobre-Fernández C., Kuzdub M., Poveda-Ortiz P., Campo-Vecino J. Del (2016) Validity and reliability of the PUSH wearable device to measure movement velocity during the back squat exercise. J. Strength Cond. Res., 30: 1968-1974. DOI: 10.1519/JSC.0000000000001284.

3. Balsalobre-Fernández C., Marchante D., Baz-Valle E., Alonso-Molero I., Jiménez S.L., Muñóz-López M. (2017) Analysis of wearable and smartphone-based technologies for the measurement of barbell velocity in different resistance training exercises. Front. Physiol., 8: 1-10. DOI: 10.3389/fphys.2017.00649.

4. Balsalobre-Fernández C., Tejero-González C.M., CampoVecino J. Del, Bavaresco N. (2014) The concurrent validity and reliability of a low-cost, high-speed camera-based method for measuring the flight time of vertical jumps. J. Strength Cond. Res., 28: 528-533. DOI: 10.1519/ JSC.0b013e318299a52e.
5. Bland J.M., Altman D.G. (2003) Applying the right statistics: Analyses of measurement studies. Ultrasound $\mathrm{Ob}$ stet. Gynecol., 22: 85-93. DOI: 10.1002/uog.122.

6. Cohen J. (1988) Statistical Power Analysis for the Behavioral Sciences (2nd ed.). Routledge. DOI: $10.4324 / 9780203771587$.

7. Conceição F., Fernandes J., Lewis M., Gonzaléz-Badillo J.J., Jimenéz-Reyes P. (2016) Movement velocity as a measure of exercise intensity in three lower limb exercises. J. Sports Sci., 34: 1099-1106. DOI: 10.1080/02640414.2015.1090010.

8. Cormie P., McBride J.M., McCaulley G.O. (2007) Validation of power measurement techniques in dynamic lower body resistance exercises. J. Appl. Biomech., 23: 103-118. DOI: 10.1123/jab.23.2.103.

9. Cronin J.B., Hing R.D., McNair P.J. (2004) Reliability and validity of a linear position transducer for measuring jump performance. J. Strength Cond. Res., 18: 590-593.

10. Dorrell H.F., Moore J.M., Smith M.F., Gee T.I. (2019) Validity and reliability of a linear positional transducer across commonly practised resistance training exercises. J. Sports Sci., 37: 67-73. DOI: 10.1080/02640414.2018.1482588.

11. García-Ramos A., Haff G.G., Pestaña-Melero F.L., PérezCastilla A., Rojas F.J., Balsalobre-Fernández C., Jaric S. (2018) Feasibility of the 2-point method for determining the 1-repetition maximum in the bench press exercise. Int. J. Sports Physiol. Perform., 13: 474-481. DOI: 10.1123/ ijspp.2017-0374.

12. García-Ramos A., Jaric S., Padial P., Feriche B. (2016) Force-velocity relationship of upper body muscles: traditional versus ballistic bench press. J. Appl. Biomech., 32: 178-185. DOI: 10.1123/jab.2015-0162.

13. Garnacho-Castaño M.V., López-Lastra S., Maté-Muñoz J.L. (2015) Reliability and validity assessment of a linear position transducer. J. Sports Sci. Med., 14: 128-136.

14. González-Badillo J.J., Sánchez-Medina L. (2010) Movement velocity as a measure of loading intensity in resistance training. Int. J. Sports Med., 31: 347-352. DOI: 10.1055/s-0030-1248333.

15. Jidovtseff B., Harris N.K., Crielaard J.-M., Cronin J.B. (2011) Using the load-velocity relationship for 1RM prediction. J. Strength Cond. Res., 25: 267-270. DOI: 10.1519/JSC.0b013e3181b62c5f.

16. Jiménez-Reyes P., Samozino P., Cuadrado-Peñafiel V., Conceição F., González-Badillo J.J., Morin J.-B. (2014) Effect of countermovement on power-force-velocity profile. Eur. J. Appl. Physiol., 114: 2281-2288. DOI: 10.1007/s00421-014-2947-1.

17. Kasovic J., Martin B., Carzoli J.P., Zourdos M.C., Fahs C.A. (2021) Agreement between the iron path app and a linear position transducer for measuring average concentric velocity and range of motion of barbell exercises. J. Strength Cond. Res., 35: S95-S101. DOI: 10.1519/JSC.0000000000003574. 
18. Lakens D. (2013) Calculating and reporting effect sizes to facilitate cumulative science: A practical primer for t-tests and ANOVAs. Front. Psychol., 4: 1-12. DOI: 10.3389/fpsyg.2013.00863.

19. Ludbrook J. (2002) Statistical techniques for comparing measurers and methods of measurement: A critical review. Clin. Exp. Pharmacol. Physiol., 29: 527-536. DOI: 10.1046/j.1440-1681.2002.03686.x.

20. Ludbrook J. (2010) Linear regression analysis for comparing two measurers or methods of measurement: But which regression? Clin. Exp. Pharmacol. Physiol., 37: 692-699. DOI: 10.1111/j.1440-1681.2010.05376.x.

21. Meylan C.M.P., Cronin J.B., Oliver J.L., Hughes M.M.G., Jidovtseff B., Pinder S. (2015) The reliability of isoinertial force-velocity-power profiling and maximal strength assessment in youth. Sport. Biomech., 14: 68-80. DOI: 10.1080/14763141.2014.982696.

22. Morin J.B., Samozino P. (2016) Interpreting power-forcevelocity profiles for individualized and specific training. Int. J. Sports Physiol. Perform., 11: 267-272. DOI: 10.1123/ijspp.2015-0638.

23. O’Donnell S., Tavares F., McMaster D., Chambers S., Driller M. (2018) The validity and reliability of the GymAware linear position transducer for measuring counter-movement jump performance in female athletes. Meas. Phys. Educ. Exerc. Sci., 22: 101-107. DOI: 10.1080/1091367X.2017.1399892.

24. Pareja-Blanco F., Rodríguez-Rosell D., Sánchez-Medina L., Sanchis-Moysi J., Dorado C., Mora-Custodio R., Yáñez-García J.M., Morales-Alamo D., Pérez-Suárez I., Calbet J.A.L., González-Badillo J.J. (2017) Effects of velocity loss during resistance training on athletic performance, strength gains and muscle adaptations. Scand. J. Med. Sci. Sport., 27: 724-735. DOI: 10.1111/sms. 12678.

25. Pérez-Castilla A., Piepoli A., Delgado-García G., Garrido-Blanca G., García-Ramos A. (2019) Reliability and concurrent validity of seven commercially available devices for the assessment of movement velocity at different intensities during the bench press. J. Strength Cond. Res., 33: 1258-1265. DOI: 10.1519/jsc.0000000000003118.

26. Pestaña-Melero F.L., Haff G.G., Rojas F.J., Pérez-Castilla A., García-Ramos A. (2018) Reliability of the load-velocity relationship obtained through linear and polynomial regression models to predict the 1-repetition maximum load. J. Appl. Biomech., 34: 184-190. DOI: 10.1123/ jab.2017-0266.

27. Rahmani A., Viale F., Dalleau G., Lacour J.-R. (2001) Force/velocity and power/velocity relationships in squat exercise. Eur. J. Appl. Physiol., 84: 227-232. DOI: 10.1007/PL00007956.

28. Rivière J.R., Rossi J., Jimenez-Reyes P., Morin J.-B., Samozino P. (2017) Where does the One-Repetition Maximum Exist on the Force-Velocity Relationship in Squat?
Int. J. Sports Med., 38:1035-1043. DOI: 10.1055/s-0043116670.

29. Samozino P., Edouard P., Sangnier S., Brughelli M., Gimenez P., Morin J.B. (2014) Force-velocity profile: Imbalance determination and effect on lower limb ballistic performance. Int. J. Sports Med., 35: 505-510. DOI: 10.1055/s-0033-1354382.

30. Samozino P., Morin J.-B., Hintzy F., Belli A. (2008) A simple method for measuring force, velocity and power output during squat jump. J. Biomech., 41: 2940-2945. DOI: 10.1016/j.jbiomech.2008.07.028.

31. Samozino P., Rejc E., Di Prampero P.E., BelliA., Morin J.B. (2012) Optimal force-velocity profile in ballistic movements-Altius: Citius or Fortius? Med. Sci. Sports Exerc., 44: 313-322. DOI: 10.1249/MSS.0b013e31822d757a.

32. Sánchez-Medina L., González-Badillo J.J., Pérez C.E., Pallarés J.G. (2014) Velocity- and power-load relationships of the bench pull vs Bench press exercises. Int. J. Sports Med., 35: 209-216. DOI: 10.1055/s-00331351252.

33. Sánchez-Medina L., Pallarés J.G., Pérez C.E., MoránNavarro R., González-Badillo J.J. (2017) Estimation of relative load from bar velocity in the full back squat exercise. Sport Med. Int. Open, 1: E80-E88. DOI: 10.1055/s0043-102933.

34. Sánchez-Pay A., Courel-Ibáñez J., Martínez-Cava A., Conesa-Ros E., Morán-Navarro R., Pallarés J.G. (2019) Is the high-speed camera-based method a plausible option for bar velocity assessment during resistance training? Meas. J. Int. Meas. Confed., 137: 355-361. DOI: 10.1016/j.measurement.2019.01.006.

35. Soler E., Mayo X., Rial-Vázquez J., Morín-Jiménez A., Aracama A., Guerrero-Moreno J.M., Slobodan J. (2019) Reliability of force-velocity parameters obtained from linear and curvilinear regressions for the bench press and squat exercises. J. Sports Sci., 37: 2596-2603. DOI: 10.1080/02640414.2019.1648993.

36. Sreckovic S., Cuk I., Djuric S., Nedeljkovic A., Mirkov D., Jaric S. (2015) Evaluation of force-velocity and power-velocity relationship of arm muscles. Eur. J. Appl. Physiol., 115: 1779-1787. DOI: 10.1007/s00421-0153165-1.

37. Zivkovic M.Z., Djuric S., Cuk I., Suzovic D., Jaric S. (2017) A simple method for assessment of muscle force, velocity, and power producing capacities from functional movement tasks. J. Sports Sci., 35: 1287-1293. DOI: 10.1080/02640414.2016.1221521.

\section{Received 23.06.2021 \\ Accepted 19.09.2021}

(C) University of Physical Education, Warsaw, Poland 